\title{
ELID grinding of silicon wafers: a literature review
}

\author{
J.H. Liu ${ }^{a}$, Z.J. Pei ${ }^{\mathrm{a}, *}$, Graham R. Fisher ${ }^{\mathrm{b}}$ \\ a Department of Industrial and Manufacturing Systems Engineering, Kansas State University, \\ Manhattan, KS 66506, USA \\ ${ }^{\mathrm{b}}$ MEMC Electronic Materials, Inc., 501 Pearl Drive, St. Peters, MO 63376, USA
}

This paper published as: Liu, J.H., Pei, Z.J., and Fisher, G.R., 2007, "ELID grinding of silicon wafers: a literature review," International Journal of Machine Tools and Manufacture, Vol. 47, No. 3-4, pp. 529-536.

\begin{abstract}
Silicon wafers are the most widely used substrates for fabricating integrated circuits. There have been continuous demands for higher quality silicon wafers with lower prices, and it becomes more and more difficult to meet these demands using current manufacturing processes. In recent years, research has been done on electrolytic in-process dressing (ELID) grinding of silicon wafers to explore its potential to become a viable manufacturing process. This paper reviews the literature on ELID grinding, covering its set-ups, wheel dressing mechanism, and experimental results. It also discusses the technical barriers that have to be overcome before ELID grinding can be used in manufacturing.
\end{abstract}

Keywords: Electrolytic in-process dressing; Grinding; Machining; Semiconductor material; Silicon wafer.

* Corresponding author. Tel.: +1 785532 3436; fax: +1 7855323738.

E-mail address: zpei@ksu.edu (Z.J. Pei). 


\section{Introduction}

Single crystal silicon is used to manufacture more than $90 \%$ of the semiconductor devices [1]. About 150 million silicon wafers of different sizes are manufactured each year worldwide [2]. As shown in Fig. 1, the major manufacturing processes for silicon wafers include crystal growth, slicing, flattening (grinding or lapping), etching, and polishing [3]. More information on these processes can be found elsewhere [4-7].

Grinding is one of the important methods in manufacturing of silicon wafers and in thinning of completed device wafers. Fig. 2 illustrates the wafer grinding process. This wafer grinding process is referred to conventional wafer grinding in this paper. During grinding, the diamond grinding wheel and the wafer rotate about their own rotation axes simultaneously, and the wheel is fed towards the wafer along its axis. The rotation axis for the grinding wheel is offset by a distance of the wheel radius relative to the rotation axis for the wafer. The challenges in grinding include the grinding marks and subsurface cracks generated on the ground wafer surfaces. These cracks could, in some cases, penetrate up to $20 \mu \mathrm{m}$ deep into the wafer [1]. In order to eliminate them, a large amount of silicon material has to be removed by the subsequent processes (such as polishing).

In order to reduce the surface roughness and subsurface damage on ground wafers, grinding wheels with smaller diamond grains are desirable. As shown in Figs. 3 and 4, better surface roughness and less subsurface damage can be obtained by using smaller diamond grains. However, when the diamond grains become very small (for example, $1 \mu \mathrm{m}$ ), it is very difficult for 
the wheel to maintain self-dressing ability [8]. (Self-dressing ability refers to the wheel's ability to release worn grains and expose new grains without any external means.)

The main benefit of ELID (electrolytic in-process dressing) grinding is that the grinding wheel is continuously dressed even if the grains are very small (up to \#3,000,000 mesh size) [9-11]. The first appearance of ELID grinding in the literature is probably in 1985, when Murata et al. [12] reported ELID grinding of ceramics using metal-bond diamond wheels with grain sizes smaller than \#400. Afterward, the ELID technique was further improved by Ohmori and Nakagawa [13]. Since 1990, studies have been done on ELID grinding of silicon wafers [1,11,13-17]. Experiments on $100 \mathrm{~mm}$ [13], $150 \mathrm{~mm}$ [16,17], and $300 \mathrm{~mm}$ [1,16] silicon wafers were reported. Diamond wheels with very small grain sizes (mesh \#1200 \#3,000,000) were used in ELID grinding $[1,11,13-17]$. And it has been reported that mirror surfaces on silicon wafers could be achieved with ELID grinding [10,13,14,16,17].

However, ELID grinding has not been accepted by the silicon wafer industry as a manufacturing process. This review paper aims to answer the following questions. What is the wheel dressing mechanism in ELID grinding? What is the state of the art? What are the technical barriers for its acceptance in manufacturing?

This paper is organized into five sections. Following this introduction section, Section 2 discusses the mechanism of wheel dressing in ELID grinding. Section 3 summarizes the set-ups for ELID grinding. Experimental results are presented in Section 4. The technical challenges for the manufacturing application of ELID grinding are discussed in Section 5. 


\section{Wheel dressing mechanism in ELID grinding}

The explanation of the ELID mechanism will need some background knowledge on electrochemistry (a field of science concerned with the relationship between electricity and chemical changes, and with the conversion of electrical and chemical energy). In a water solution, the molecules of an acid, base, or salt are dissociated into positively and negatively charged ions. These ions allow electric current to be conducted, playing the same role that electrons play in metallic conduction. The ionized solution is called an electrolyte. Electrolytic conduction requires that current enter and leave the solution at electrodes. The positive electrode is called the anode and the negative electrode is the cathode. At each electrode, some chemical reaction occurs, such as the deposition or dissolution of material. Electrolysis is the name given to these chemical changes occurring in the solution.

During ELID grinding, the electrically-conductive grinding wheel is connected to the positive terminal of a power and a negative electrode is put near the wheel surface. By supplying the current and electrolytic fluid into the small gap between the electrode and the grinding wheel, electrolysis is generated and the dressing process starts.

The ELID mechanism is illustrated in Fig. $5[10,13,14,18]$. Before grinding, a pre-dressing process using the ELID method is required for the purpose of maintaining the protrusion of diamond grains on the wheel surface. As shown in Fig. 5(a), the bond material on the wheel surface is dissolved electrolytically, and the non-conductive diamond grains are exposed. During the dressing process, an insulating film comprising iron oxide is formed on the surface of the 
wheel, and the electric resistance of the wheel is then increased. The film formation causes both the electric current and the dissolution of the bond material to decrease. As shown in Fig. 5(b), the electrolytic phenomenon is gradually reduced and stabilized towards the end of the dressing. During grinding, the insulating film and diamond grains are scraped off and removed, as shown in Fig. 5(c) and (d). The insulating film is worn off from the wheel surface, resulting in a decrease of the wheel's electrical resistance and an increase of the electric current between the wheel and the electrode. Therefore, the dissolution of bond material increases and the exposure of diamond grains restarts. This ELID cycle continues during the ELID grinding process [19].

It was suggested that this process not only helped expose new sharp diamond grains, but also reduced bond strength of the wheel surface by electrolysis [20]. According to Fathima et al. [20], the reduction of bond strength would reduce the depth-of-cut of diamond grains and improve the surface finish.

\section{Set-ups for ELID grinding}

As shown in Fig. 6, the basic ELID system consists of a diamond grinding wheel, an electrode, a power supply, and electrolytic fluid.

\subsection{ELID grinding wheels}

For ELID grinding, either straight $[11,14,16,21]$ or cup-shaped $[9,13]$ wheels have been used. These two shapes are illustrated in Fig. 7. 
Diamond has been exclusively used as the abrasives in the grinding wheels for ELID grinding of silicon wafers. The diamond grain sizes ranged from \#1200 (average grain diameter $\approx 7 \mu \mathrm{m}$ ) to $\# 3,000,000$ (average grain diameter $\approx 5 \mathrm{~nm}$ ) $[11,14]$. As shown in Fig. 8, the diamond grains used in ELID grinding were much smaller than that used in conventional wafer fine grinding.

The bonds used in ELID wheels were mostly metal bonds $[9,13,14,16]$. Both cast iron and copper have been used as the bonding material for metal-bond wheels [22].

However, Ohmori et al. [23] reported that ELID grinding using metal-bond wheels had problems of workpiece "chipping" and "scratches" on the workpiece by the chips. And the obtained ground surfaces merely had a $\mathrm{R}_{\max }$ of about 18 to $20 \mathrm{~nm}$. To solve this problem, metal-resin bond wheels with a variety of diamond grain sizes $(\# 8000, \# 120,000$, and \#3,000,000) were developed [11,23]. Using wheels with mesh \#3,000,000, surface roughness with $\mathrm{R}_{\max }$ of $2.8 \mathrm{~nm}$ [11] and $1.85 \mathrm{~nm}$ [23] could be achieved on ground silicon wafers.

In addition, in ELID grinding, the metal ions in the metal-bond wheels would dissociate in the grinding fluid during the electrolytic dressing. The waste fluid containing these heavy metal ions could result in environmental pollution [21]. Moreover, these metal ions (particularly, copper and tin) could cause poor device performance when ELID grinding device wafers [21]. In order to prevent contamination of the device wafers by metal ions, Itoh and Ohmori [21] developed a carbon-based metal-free conductive bond wheel for ELID grinding. They used diamond abrasives (\#8000; average diameter of $2 \mu \mathrm{m}$ ), carbon, and phenol resins to make the wheel. The mixing ratio of carbon to resin was 1:5. 


\subsection{Electrode and power supply}

Arc-shaped electrodes were used in ELID grinding for both straight and cup type wheels [22]. The length of the electrode could be $1 / 4$ or $1 / 6$ of the perimeter of the grinding wheel, and the gap between the electrode and the grinding wheel was 0.1 to $0.3 \mathrm{~mm}$ [22]. Usually, copper or graphite was selected as the electrode material [22].

The power supply controls the electric current, voltages and pulse width for the ELID process [22]. The typical values of the applied voltage were $60 \sim 90 \mathrm{~V}[9,11,14,16-18]$.

\subsection{Machine set-ups}

An important feature of the ELID grinding is that it can be retrofitted on conventional grinding or lapping machines [13]. Table 1 summarizes the type of machines that have been used for ELID grinding of silicon wafers.

Itoh et al. conducted ELID grinding of silicon wafers on a lapper [11]. In their set-up, as shown in Fig. 9, the wafer was pressed onto a grinding wheel that was in the place of the lapping plate. The wheel was connected to the positive terminal of a power supply by a brush. The negative electrode was fixed above the wheel at a distance of about $0.3 \mathrm{~mm}$. A conductive fluid was provided between the negative electrode and the wheel surface. The set-ups of this kind are, generally speaking, not practical for manufacturing of large diameter wafers, since the wheel diameter needs to be at least twice as large as the wafer diameter. 
In addition, ELID grinding of silicon wafers was done on a horizontal spindle surface grinding machine using a straight type wheel [16], as shown in Fig. 10. This set-up would make it possible to grind a large wafer without using a large grinding wheel. The silicon wafer (workpiece) was held on a rotary table. The speed of the rotary table would have to change according to the position of the wheel to keep the relative speed at the interface between the wheel and the wafer (approximately) constant.

ELID grinding has also been applied to double side grinding [24]. As shown in Fig. 11, the driving rollers were rotated by the driving device, and they were individually pressed against the periphery of the wafer to rotate the wafer. During the grinding process, both sides of the wafer were ground simultaneously by a pair of wheels. In this way, the surface of a large wafer (400 $\mathrm{mm}$ for instance) can be ground without using a large wheel. Note that this double side grinding set-up is different from the simultaneous double side grinding process used in silicon wafer manufacturing [25].

For the above two set-ups, it is very difficult to achieve super flatness on ground wafers. Note that either the wheel or the wafer has to move constantly in order to grind the entire wafer surface. Furthermore, the (vertical) position of the wheel has to be constantly adjusted to compensate the wheel radial wear.

The layout of the vertical spindle surface grinding machine using a cup-type wheel is shown in Fig. 6. The wafer center is offset by the wheel radius from the wheel center. The silicon wafer (and the work spindle) rotates at a relatively lower speed, and the wheel rotates at a higher speed. 
This set-up is similar to the conventional wafer grinding shown in Fig. 2.

\section{Experimental results}

Several experiments (as summarized in Table 2) have been conducted on ELID grinding of silicon wafers. These experiments are presented in this section according to the following aspects of grinding performance: surface roughness of ground wafers, subsurface damage introduced in the ground wafers, material remove rate, and flatness of ground wafers.

\subsection{Surface roughness}

When studying the effects of diamond grain size, some researchers used straight wheels on a lapping machine $[11,14,21]$, while others used straight [16] or cup-type wheels $[9,13]$ on vertical spindle surface grinding machines. These researchers reported consistent results: with smaller diamond grains, better surface roughness could be achieved on ground wafers (as shown in Fig. 12). Using resin-metal bond wheels with the diamond grain size of $\# 3,000,000$, a surface roughness of $1.85 \mathrm{~nm}$ in $\mathrm{R}_{\max }$ was achieved [23].

Islam et al. [17] studied the ground wafer surfaces using different injection flow rates $(31.41 \mathrm{l} / \mathrm{h}$ and $92 \mathrm{l} / \mathrm{h}$ ) of electrolyte (also used as coolant). The experiment was carried out on a CNC machining center. The wheel used was a metal-bond cup wheel. The diamond grain size of the

wheel was \#8000, and the wheel diameter and width were $200 \mathrm{~mm}$ and $5 \mathrm{~mm}$, respectively. Silicon wafers with thickness of $0.75 \mathrm{~mm}$ and diameter of $152.4 \mathrm{~mm}$ were used. They reported 
that ELID grinding with lower injection flow rate generated smoother ground surfaces on silicon wafers. The surface roughness of the ground surface was $2 \mathrm{~nm}$ in $\mathrm{R}_{\mathrm{a}}$.

In summary, experiments have demonstrated that ELID grinding could achieve very good surface roughness. $\mathrm{R}_{\max }$ of less than $2 \mathrm{~nm}$ has been reported $[9,11,13]$. Note that typical surface roughness obtained with conventional wafer grinding using \#2000 resin-bond wheels was $10 \mathrm{~nm}$ in $\mathrm{R}_{\mathrm{a}}$ [3].

\subsection{Subsurface damage}

Ohmori and Nakagawa [9] studied subsurface damage in ELID ground silicon wafers by means of X-ray. When ground by \#2000, \#4000, \#6000, and \#8000 wheels, subsurface damage (cracks) existed in ground surfaces with $\mathrm{R}_{\mathrm{a}}$ of several namometers. In order to evaluate the cracks generated by different diamond grain sizes, the ground wafer surfaces were polished and treated with a chemical etching. As shown in Fig. 13, the depth of cracks could be reduced by using smaller grain sizes, and the \#8000 wheel could reduce the crack depth to below $1 \mu \mathrm{m}[9]$.

Ohmori and Nakagawa [9] also evaluated the depth of subsurface damage on ELID ground wafers by step-etching. They found that the damaged layer caused by the metal-bond wheel of diamond grain size of $\# 40,000$ was completely removed after $1 \mu \mathrm{m}$ thick of silicon was removed from the ground surfaces by etching.

Such level of subsurface damage has not been achieved in conventional wafer grinding. Typical values for the depth of subsurface cracks induced in conventional wafer grinding were $2 \mu \mathrm{m}$ and above [26,27]. 


\subsection{Material removal rate}

As diamond grains get smaller, ground surfaces get smoother and the depth of subsurface cracks gets smaller; but the material removal rate will be slower (as shown in Fig. 14).

Itoh et al. [11] showed that, under the same grinding condition, wheels with smaller diamond grains would remove material at a lower rate (see Fig. 15). The wheels used were metal-resin bond wheels. All the wheels tested (including the one with $\# 3,000,000$ diamond grains) showed stable grinding. However, the material removal rate became much smaller when the diamond grains were smaller.

Itoh and Ohmori [21] compared metal-free conductive-bond wheels and metal-bond wheels (both with diamond grain size of \#8000) using a lapping machine. Fig. 16 illustrates the relationship between the grinding pressure and material remove rate (the thickness of silicon removed from the wafer surface per minute). It can be seen that material removal rate of the metal-free conductive-bond wheels was much lower than that of the metal-bond wheels.

In summary, the material removal rate in ELID grinding (about $1 \mu \mathrm{m} / \mathrm{min}$ even for $\# 8000$ diamond grains) was much lower than that in conventional wafer grinding (typically, more than $10 \mu \mathrm{m} / \mathrm{min})[28,29,30]$.

\subsection{Flatness}


As the starting materials for fabrication of most integrated circuits, silicon wafers must be very flat in order to print circuits on them by lithographic processes [31]. The flatness of silicon wafers directly impacts device line-width capability, process latitude, yield, and throughput [32,33]. Wafer flatness can be characterized in terms of a global or site parameter. The global parameter most commonly used is GBIR, or total thickness variation (TTV). A frequently used parameter to measure the site flatness is SFQR (site flatness, front reference surface, best-fit reference plane, range) [34]. It is the sum of the maximum positive and negative deviations of the surface in a certain area of the wafer from a theoretical reference plane that is determined by the best-fit method. Typical size of the area is $26 \times 33 \mathrm{~mm}^{2}$. The flatness requirements in recent years are shown in Table 3 [34].

No experimental data are available to demonstrate that ELID grinding can achieve the flatness requirements on silicon wafers. Note that none of the grinding experiments reported (see Table 1) was conducted on the industry standard wafer grinders. These grinders include various models from Disco [35], G\&N [36], Koyo [37], Okamoto [38], and Strasbaugh [39]. These wafer grinders can routinely produce a flatness of less than $1 \mu \mathrm{m}$ in TTV on $200 \mathrm{~mm}$ and $300 \mathrm{~mm}$ wafers.

Unless ELID grinding can produce super flat wafers, its acceptance in silicon wafer manufacturing will remain questionable.

\section{Concluding remarks}


For silicon wafer grinding (especially fine grinding), it is desirable to use grinding wheels with very small diamond grains to achieve better surface roughness and less subsurface damage on ground wafers. However, it is very difficult, if not impossible, to manufacture grinding wheels, using diamond gains smaller than \#4000 mesh, with sufficient self-dressing ability.

Because an ELID grinding wheel is dressed continuously by the electrolysis mechanism, it can be made from very small diamond grains (such as $\# 3,000,000$ mesh). Experimental results have shown that ELID grinding can achieve better surface roughness and less subsurface damage than those obtained by conventional wafer grinding.

However, several technical barriers associated with ELID grinding have to be overcome before it becomes a viable manufacturing process. For example, no evidence is available to show that ELID grinding can achieve the super wafer flatness that conventional wafer grinding can routinely achieve. Furthermore, the material removal rate with ELID grinding is very low compared to conventional wafer grinding.

Another challenge with ELID grinding is that, as the wheels are dressed during the grinding process, the wheel wear must be compensated in order to obtain high dimensional accuracy [20]. Furthermore, the macrofracture of the oxide layer (shown in Fig. 5(b)) has been reported as a problem with ELID grinding. If the thickness of the layer removed from the wheel surface during macrofracture was greater than the grain size of the wheel, the sharp new diamond grains were also removed along with the fractured layer [20]. This would waste diamond grains and result in a shorter wheel life [20]. The friction and wear properties of the oxide layer are not well understood yet [40]. 


\section{Acknowledgements}

The work was supported by the National Science Foundation through the CAREER Award DMI-0348290.

\section{References}

[1] C.L. Chao, K.J. Ma, S.C. Sheu, H.Y. Lin, F.Y. Chang, Investigation of the surface integrity of precision machined single crystal silicon, Proceedings of the $15^{\text {th }}$ Annual Meeting of The American Society for Precision Engineering, October 22-27, 22 (2000) 82-85.

[2] M. Tricard, S. Kassir, P. Herron, Z.J. Pei, New abrasive trends in manufacturing of silicon wafers, Proceedings of Silicon Machining Symposium, American Society of Procesion Engineering, St. Louis, MO, USA (1998).

[3] Z.J. Pei, A. Strasbaugh, Fine grinding of silicon wafers: designed experiments, International Journal of Machine Tools and Manufacture 42 (3) (2002) 395-404.

[4] M.S. Bawa, E.F. Petro, H.M. Grimes, Fracture strength of large diameter silicon wafers, Semiconductor International 18 (11) (1995) 115-118.

[5] T. Fukami, H. Masumura, K. Suzuki, H. Kudo, Method of manufacturing semiconductor mirror wafers, European Patent Application EP96111698.5, 1997.

[6] H.K. Tonshoff, W.V. Schmieden, I. Inasaki, W. Konig, G. Spur, Abrasive machining of silicon, Ann. CIRP 39 (2) (1990) 621-630.

[7] R. Vandamme, Y. Xin, Z.J. Pei, Method of processing semiconductor wafers, US Patent 6,114,245, 2000.

[8] K. Carlisle, M.A. Stocker, Cost-effective machining of brittle materials (glasses and ceramics) eliminating/minimizing the polishing process, Proceedings of The International Society for Optical Engineering 3099 (1997) 46-58.

[9] H. Ohmori, T. Nakagawa, Analysis of mirror surface generation of hard and brittle materials by ELID (electronic in-process dressing) grinding with superfine grain metallic bond wheels, Annals of CIRP 44 (1) (1995) 287-290.

[10] H. Ohmori, Method and apparatus for grinding with electrolytic dressing, US Patent 5,547,414, 1996. 
[11] N. Itoh, H. Ohmori, S. Moriyasu, T. Kasai, T.K. Doy, B.P. Bandyopadhyay, Finishing characteristics of brittle materials by ELID-lap grinding using metal-resin bonded wheels, International Journal of Machine Tools \& Manufacture 38 (7) (1998) 747-762.

[12] R. Murata, K. Okano, C. Tsutsumi, Grinding of structural ceramics, Proceedings of the Milton C. Shaw Grinding Symposium, PED 16 (1985) 261-272.

[13] H. Ohmori, T. Nakagawa, Mirror surface grinding of silicon wafers with electrolytic in-process dressing, Annals of CIRP 39 (1) (1990) 329-332.

[14] N. Itoh, H. Ohmori, Grinding characteristics of hard and brittle materials by fine grain lapping wheels with ELID, Journal of Materials Processing Technology 62 (4) (1996) $315-320$.

[15] Y. Chang, Y.T. Hung, J.H. Tsai, C.L. Chao, S.C. Chang, T.H. Lin, Y.P. Chiu, C.C. Wang, $\mathrm{Si}-\mathrm{O}-\mathrm{Si}$ bonding configurations of damaged layer formed after diamond grinding and chemomechanical polishing of Si wafers, Proceedings of International Symposium on Advances in Abrasive Technology, NSW Australia, July 8-10, (1997) 38-42.

[16] I.D. Marinescu, C. Miyakawa, H. Ohmori, J. Shibata, ELID grinding characteristics of silicon wafer, Proceedings of the first International Conference of Precision engineering nanotechnology 1 (1999) 380-383.

[17] M.M. Islam, A.S. Kumar, S. Balakumar, H.S. Lim, M. Rahman, Advanced ELID process development for grinding silicon wafers, Proceedings of Materials Research Society Symposium 867 (2005) 97-104.

[18] H.S. Lim, K. Fathima, A.S. Kumar, M. Rahman, A fundamental study on the mechanism of electrolytic in-process dressing (ELID) grinding, International Journal of Machine Tools \& Manufacture 42 (8) (2002) 935-943.

[19] M.P. Groover, Fundamentals of modern manufacturing, Second edition, John Willy \& Sons, Inc., New York, 2002.

[20] K. Fathima, A.S. Kumar, M. Rahman, H.S. Lim, A study on wear mechanism and wear reduction strategies in grinding wheels used for ELID grinding, Wear 254 (12) (2003) 1247-1255.

[21] N. Itoh, H. Ohmori, Development of metal-free conductive bonded diamond wheel for environmentally-friendly electrolytic in-process dressing (ELID) grinding, New Diamond and Frontier Carbon Technology 14 (4) (2004) 227-238.

[22] M. Rahman, A.S. Kumar, H.S. Lim, K. Fatima, Nano finish grinding of brittle materials using electrolytic in-process dressing (ELID) technique, Sadhana 28 (5) (2003) 957-974.

[23] H. Ohmori, N. Itoh, T. Kasai, T. Karaki-Doy, K. Horio, T. Uno, M. Ishii, Metal-resis bond grindstone and method for manufacturing the same, US Patent 6,203,589, 2001.

[24] H. Ohmori, Apparatus and method for ELID grinding a large-diameter workpiece to produce a mirror surface finish, US Patent 6,537,139, 2003.

[25] Z.C. Li, Z.J. Pei, G.R. Fisher, Simultaneous double side grinding of silicon wafers: a literature review, accepted to appear in International Journal of Machine Tools and Manufacture. 
[26] Z.J. Pei, S.R. Billingsley, S. Miura, Grinding-induced subsurface cracks in silicon wafers, International Journal of Machine Tools and Manufacture 39 (7) (1999) 1103-1116.

[27] H. Lundt, M. Kerstan, A. Huber, P.O. Hahn, Subsurface damage of abraded silicon wafers, Proceedings of 7th international symposium on silicon materials science and technology, The Electrochemical Society, Pennington, NJ 94-10 (1994) 218-224.

[28] Z.J. Pei, A Study on surface grinding of $300 \mathrm{~mm}$ silicon wafers, International Journal of Machine Tools and Manufacture 42 (3) (2002) 385-393.

[29] Z.J. Pei, A. Strasbaugh, Fine grinding of silicon wafers, International Journal of Machine Tools and Manufacture 41 (5) (2001) 659-672.

[30] Z.J. Pei, G.R. Fisher, M. Bhagavat, S. Kassir, A grinding-based manufacturing method for silicon wafers: an experimental investigation, International Journal of Machine Tools and Manufacture 45 (10) (2005) 1140-1151.

[31] X.H. Zhang, Z.J. Pei, G.R. Fisher, A grinding-based manufacturing method for silicon wafers: generation mechanisms of central dimples on ground wafers, International Journal of Machine Tools and Manufacture 46 (3-4) (2006) 397-403.

[32] M. Kulkarni, A. Desai, Silicon wafering process flow, US Patent 6,294,469, 2001.

[33] H.S. Oh, H.L. Lee, A Comparative Study between Total Thickness Variance and Site Flatness of Polished Silicon Wafer, Japanese Journal of Applied Physics 40 (2001) $5300-5301$.

[34] SEMI, Specifications for Polished Mono-crystalline Silicon Wafers, SEMI M1-0600, Semiconductor Equipment and Materials International, San Jose, CA, 2000.

[35] Disco Website, <http://www.disco.co.jp>.

[36] G\&N Website, $<$ http://www.grinders.de/e-index.htm>.

[37] Koyo Website, <http://www.crystec.com/kllovere.htm>.

[38] Okamoto Website, $<$ http://www.okamoto-sed.com/index.html $>$.

[39] Strasbaugh Website, <http://www.strasbaugh.com/about.cfm>.

[40] T. Kato, H. Ohmori, K. Katahira, N. Itoh, N. Mituishi, A. Nemoto, Friction and wear properties of an ELID-grinding wheel based on CCD microscope observation, Key Engineering Materials 238-239 (2003) 307-312.

[41] Asahi Diamond Industrial, 2000, "Diamond \& CBN wheels," retrieved from: $<$ http://www.asahidia.co.jp/pdf/B07.pdf $>$.

[42] Z.J. Pei, S.R. Billingsley, S. Miura, Grinding induced subsurface cracks in silicon wafers, International Journal of Machine Tools and Manufacture 39 (1999) 1103-1116. 


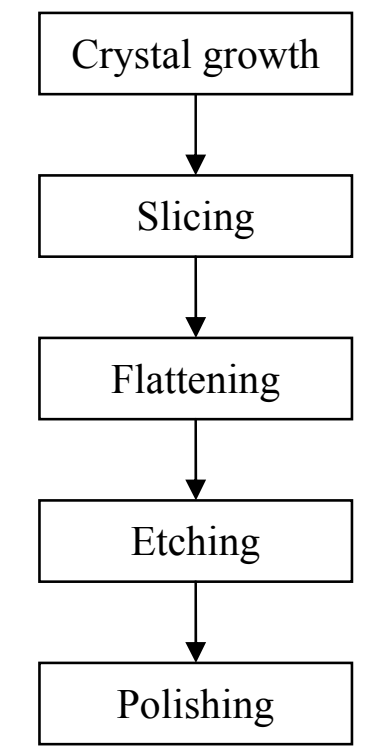

Fig. 1. Major manufacturing processes for silicon wafers (after [3]). 


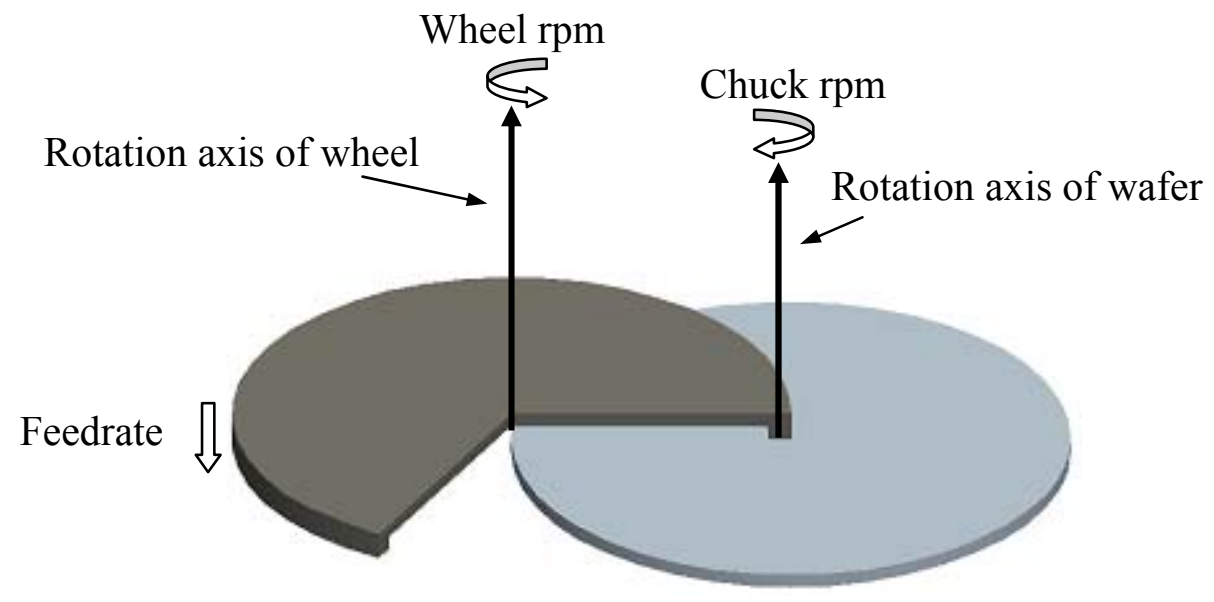

Fig. 2. Illustration of conventional wafer grinding (after [31]). 


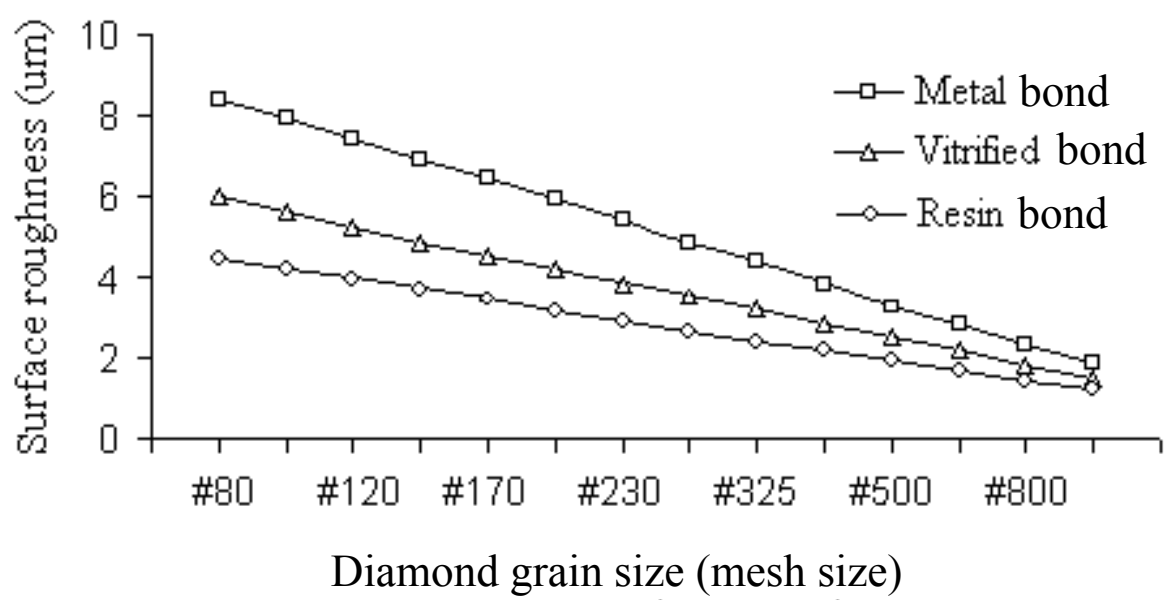

Fig. 3. Relationship between diamond grain size and surface roughness when grinding ceramics (after [41]). 


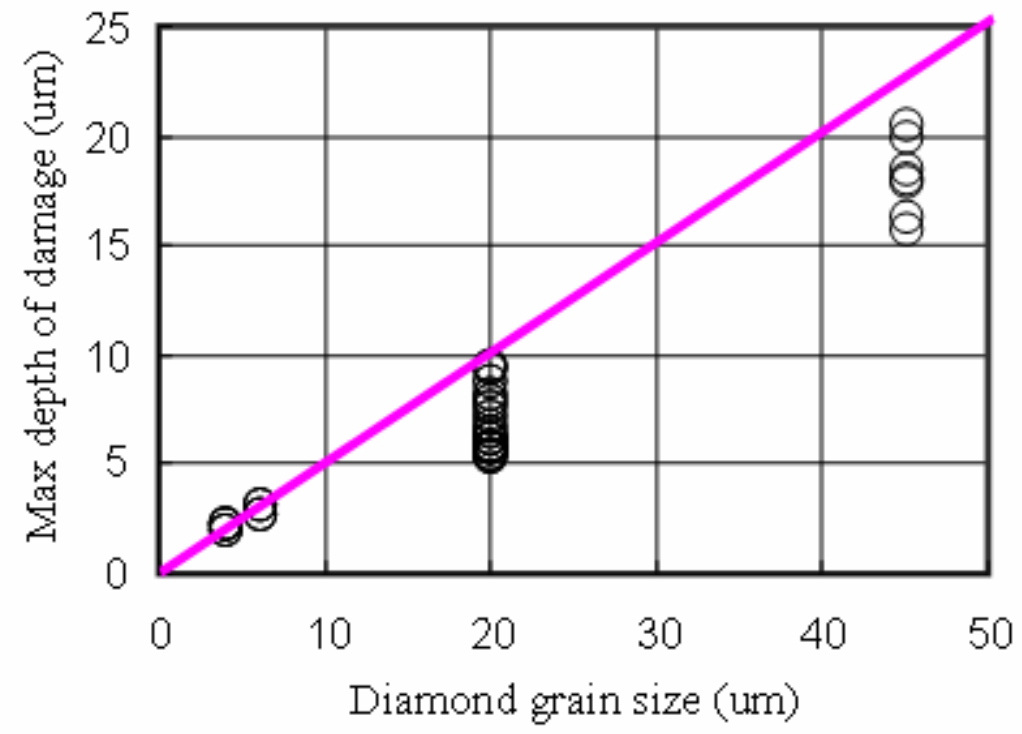

Fig. 4. Relation between diamond grain size and maximum depth of cracks [42]. 
(a) Pre-dressing

(b) End of dressing

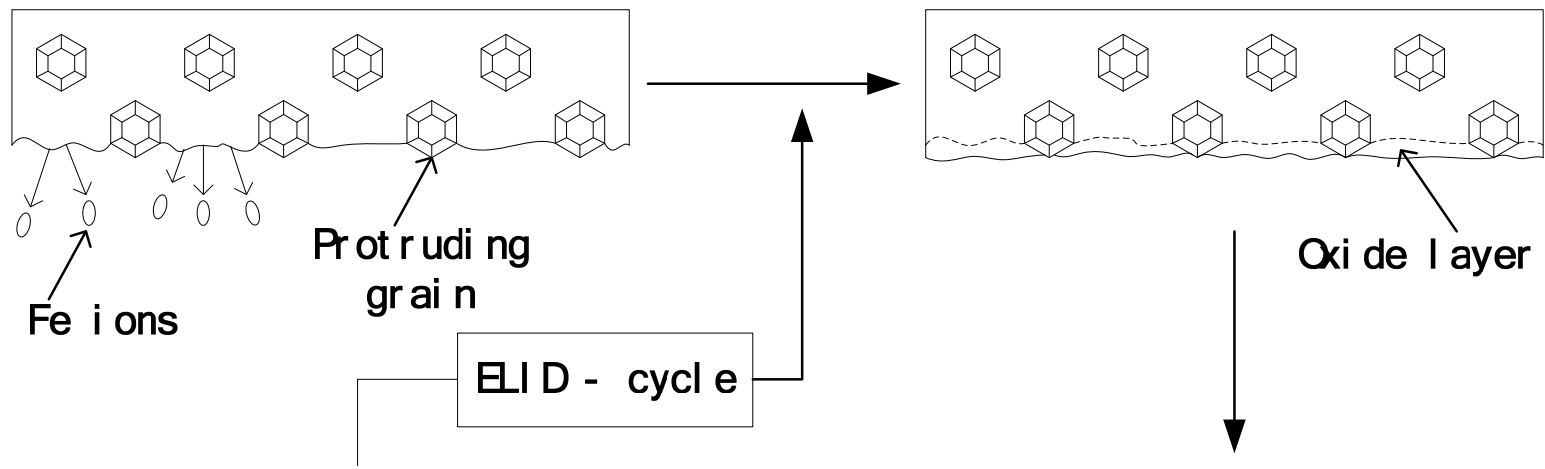

(d) Stabi I i zati on of El D

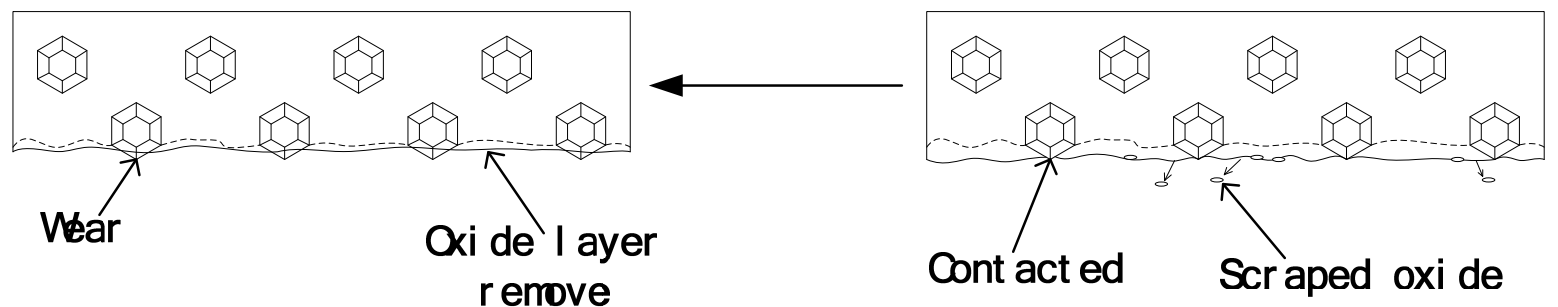

Fig. 5. Mechanism of ELID grinding (after [13,14,16,18,40]). 


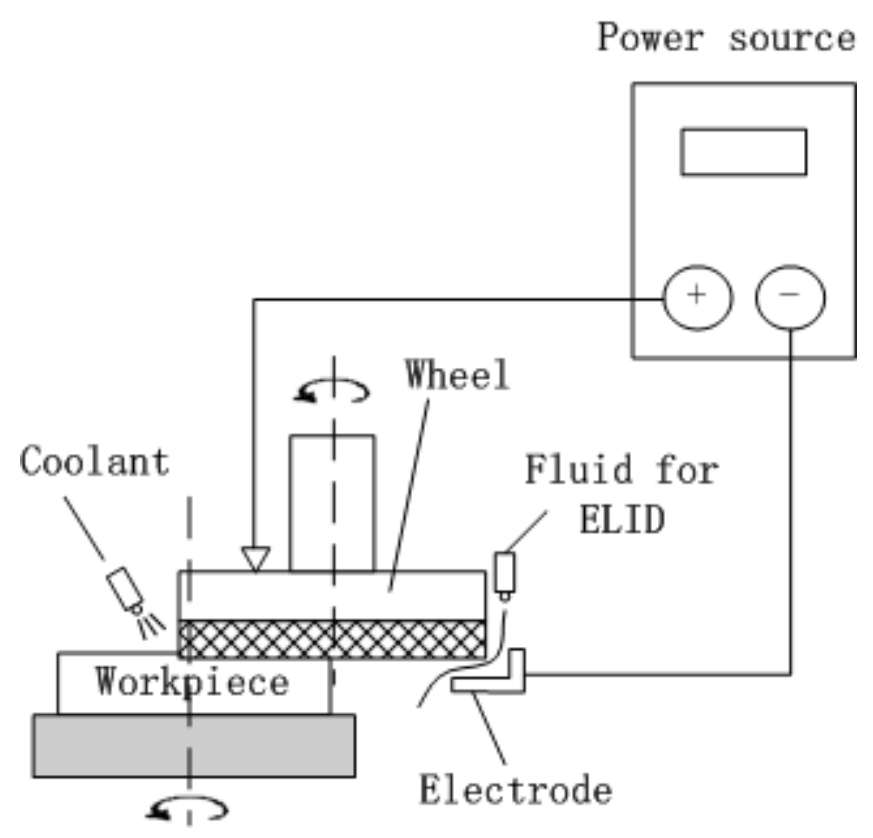

Fig. 6. Basic ELID system (after [9]). 


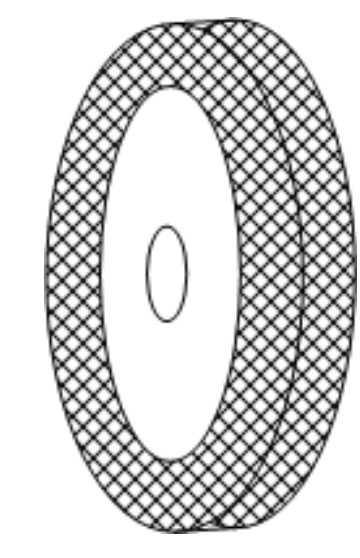

(a) Straight type

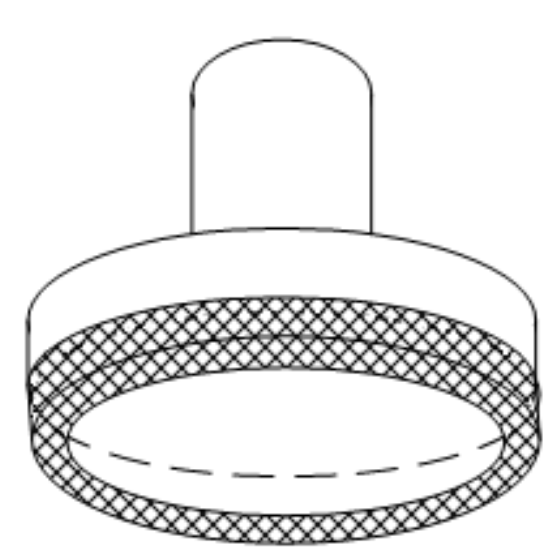

(b) Cut type

Fig. 7. Two types of diamond wheels for ELID grinding. 


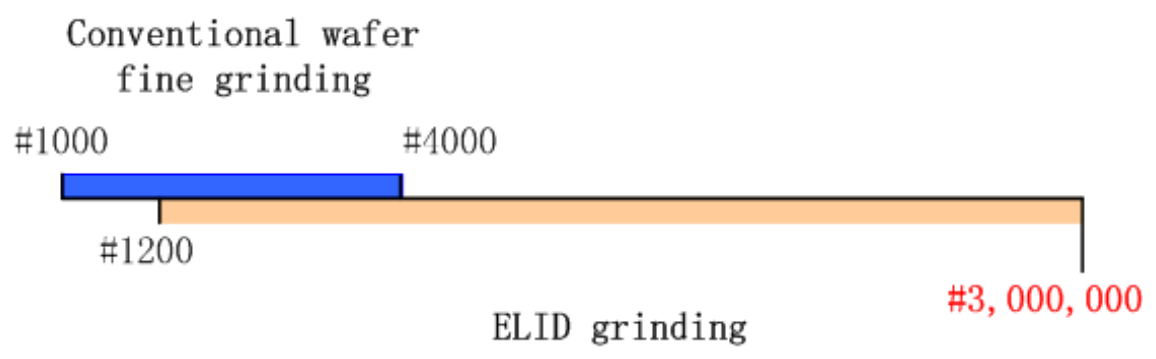

Fig. 8. Diamond grain sizes (mesh sizes) for ELID grinding and conventional wafer fine grinding (after $[1,11,25])$. 


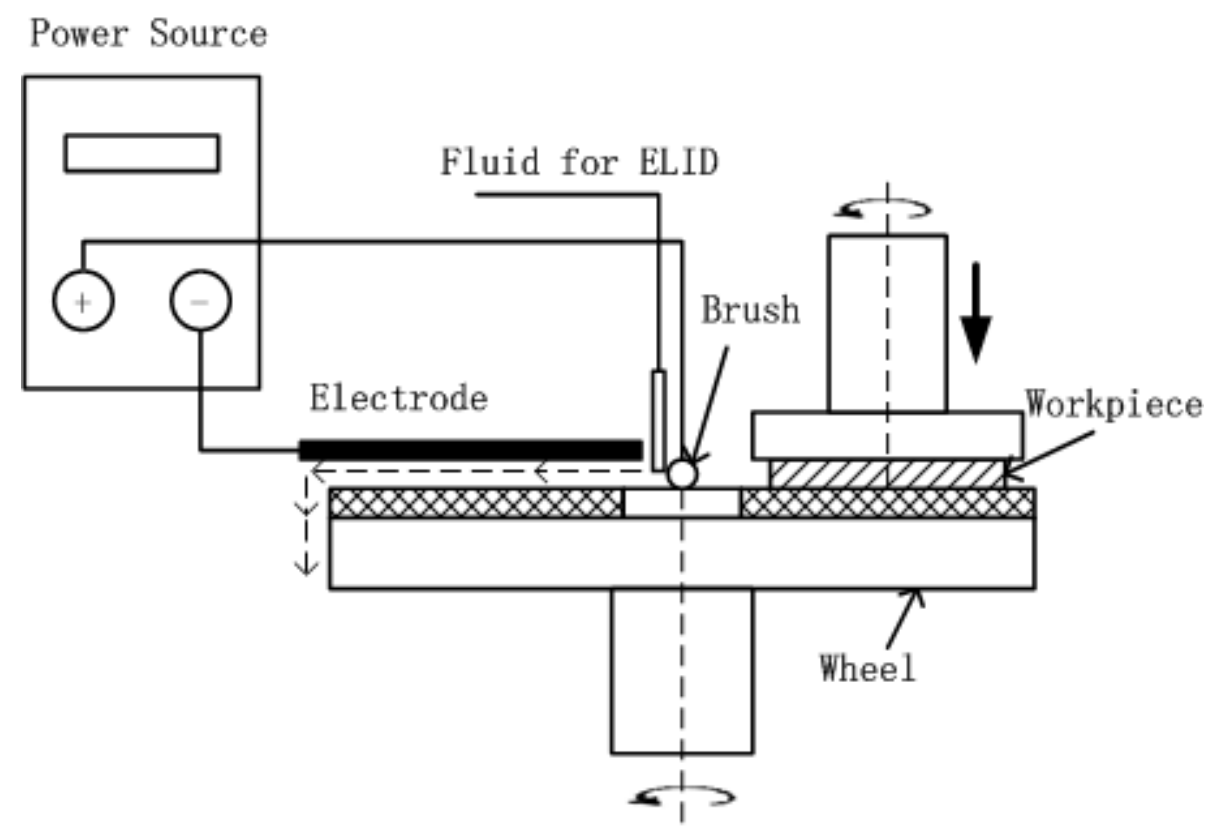

Fig. 9. ELID grinding on a lapper (after $[11,14]$ ). 


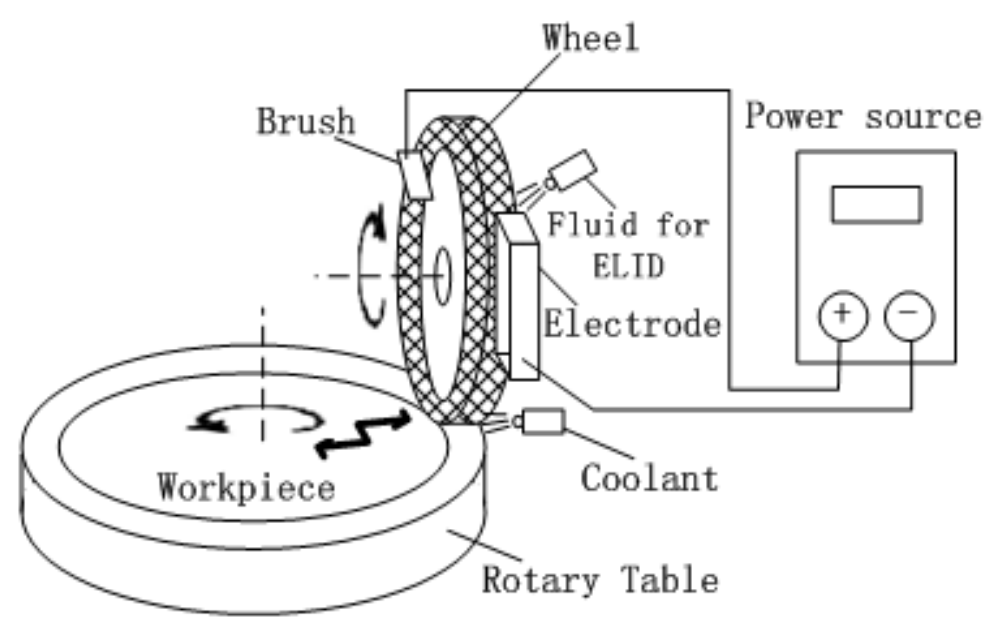

Fig. 10. ELID grinding using a straight wheel on a horizontal spindle (after [16]). 


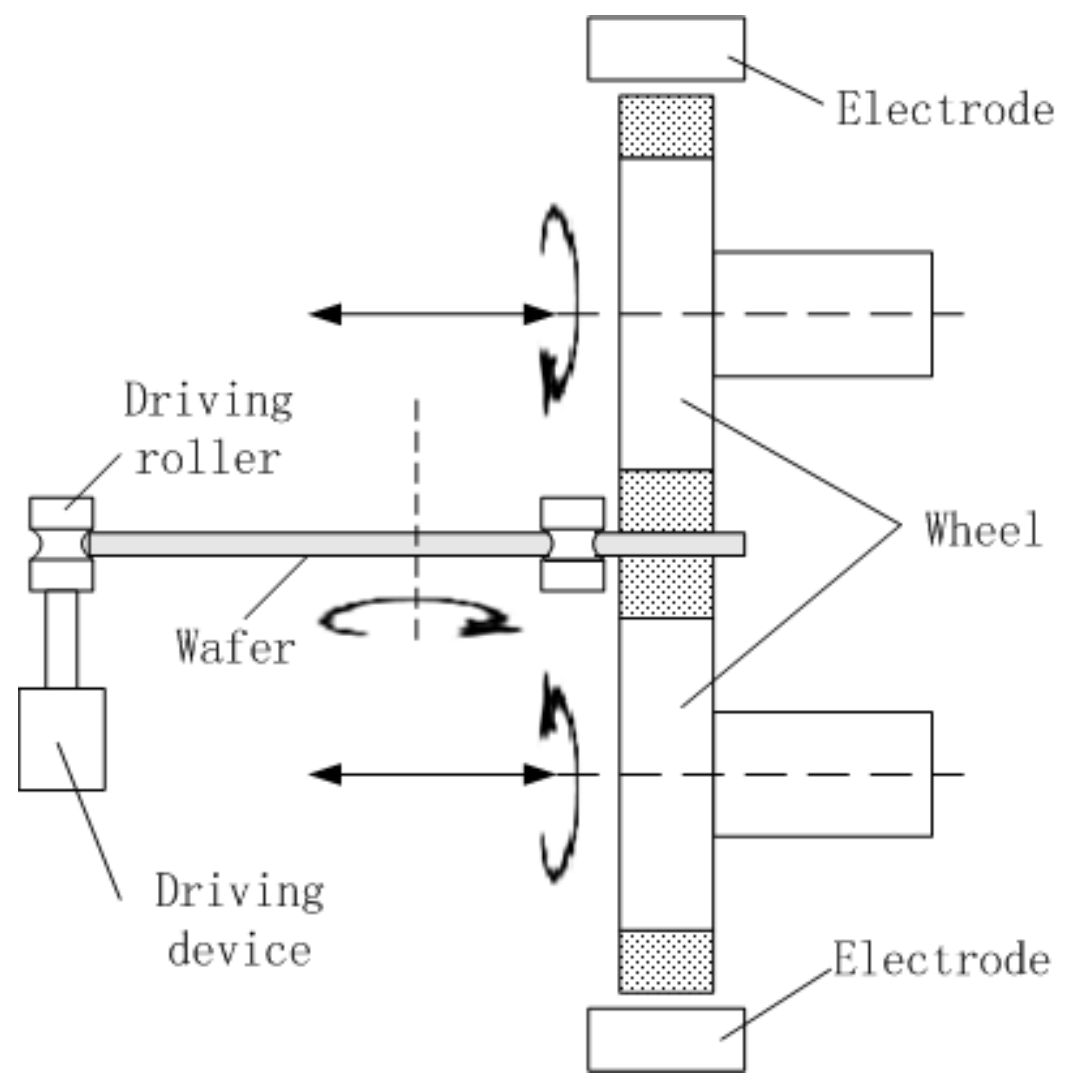

Fig. 11. ELID double-side wafer grinding using a pair of straight wheels (after [24]). 


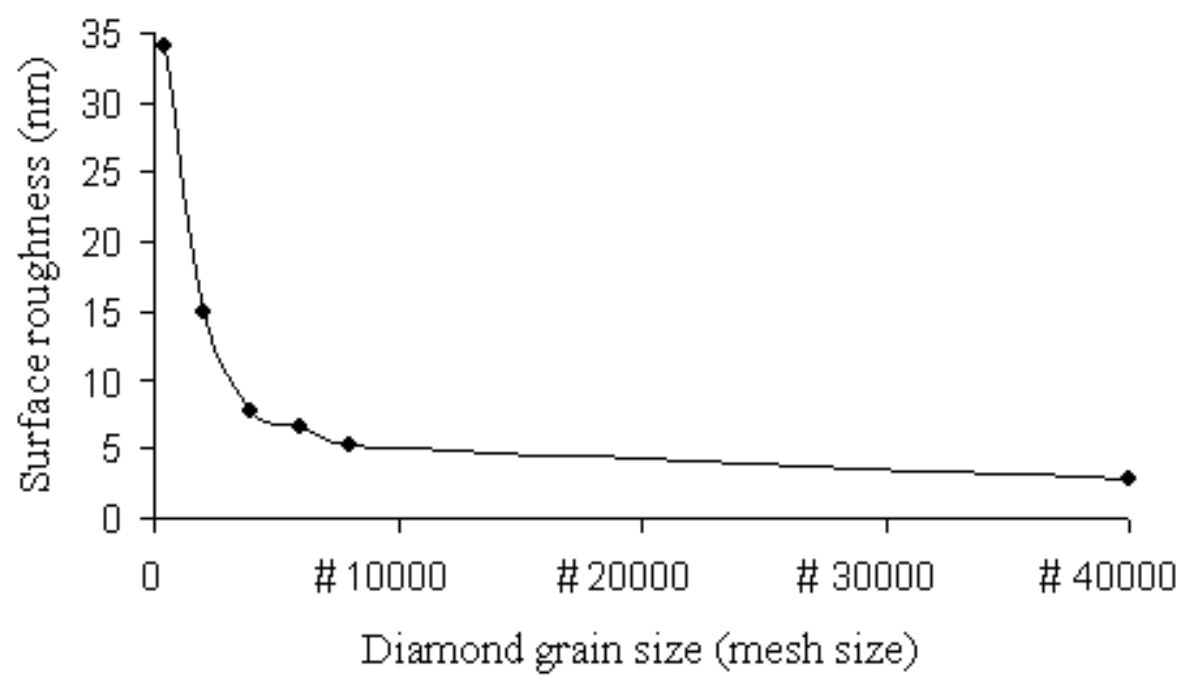

Fig. 12. Effects of diamond grain size on surface roughness of ground silicon wafers (after [9]). 


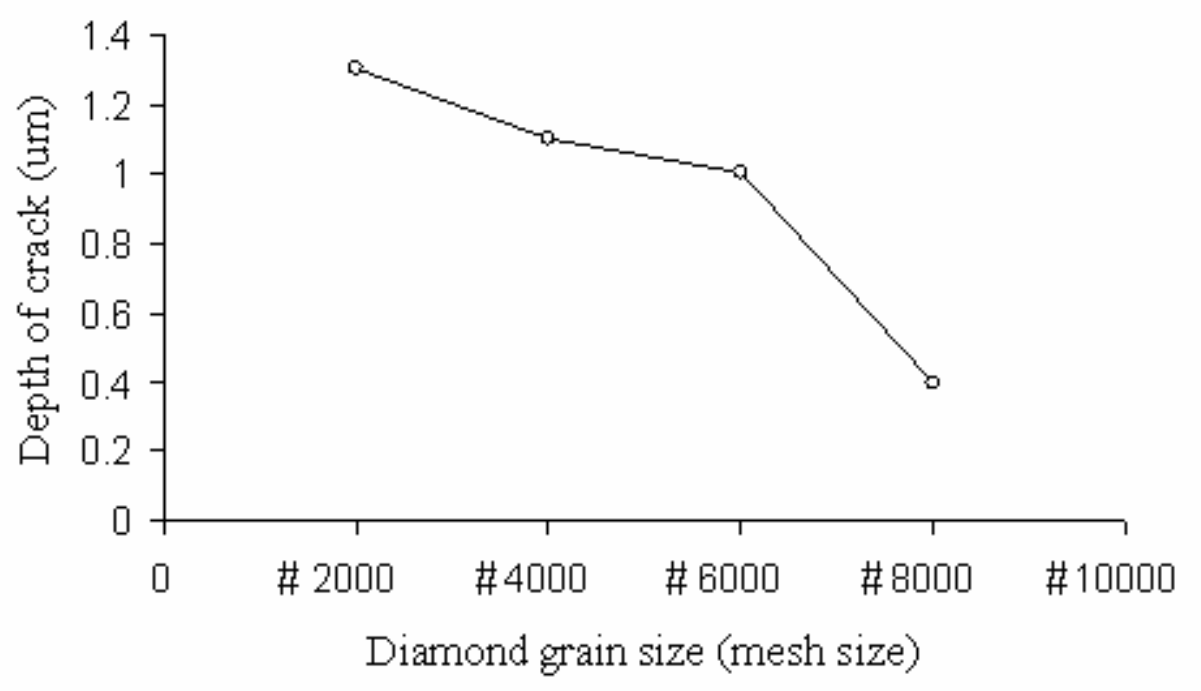

Fig. 13. Relation between the depth of subsurface cracks and diamond grain size in ELID grinding (after [9]). 


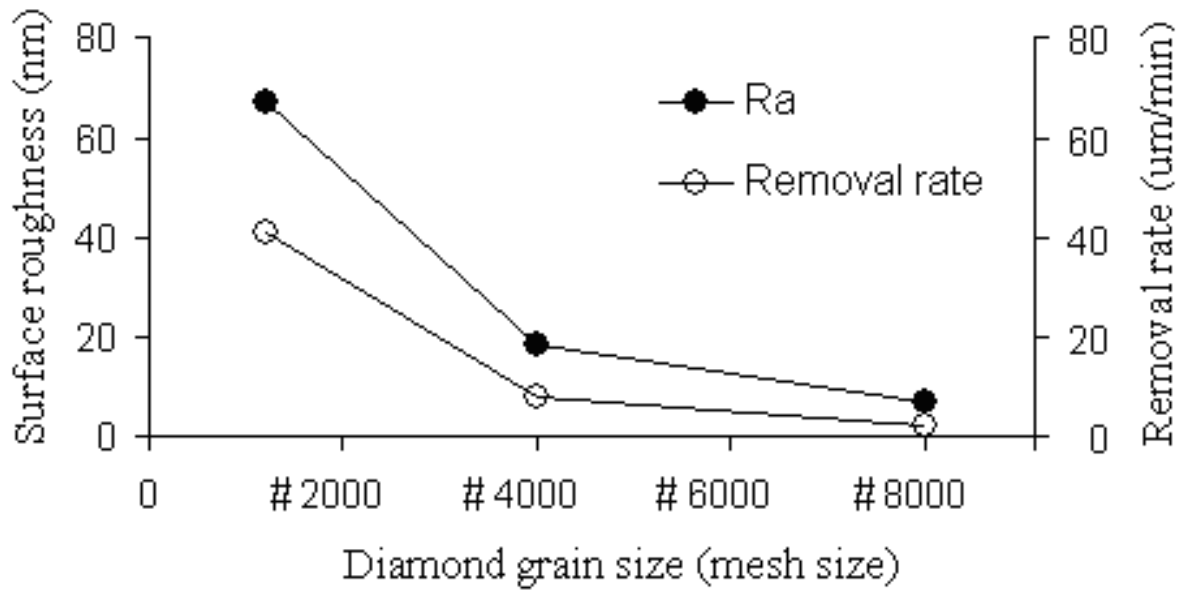

Fig. 14. Effects of diamond grain size on surface roughness and material removal rate (after [14]). 


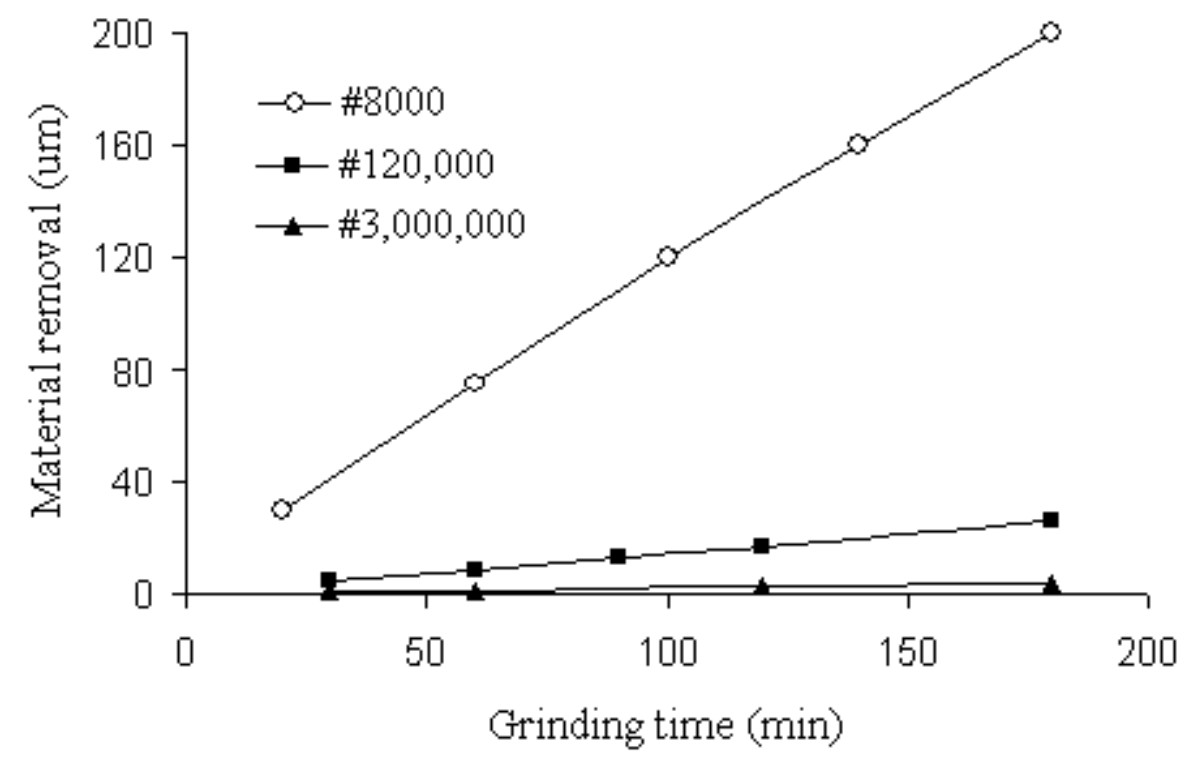

Fig. 15. Effects of diamond grain size on material removal rate (after [11]). 


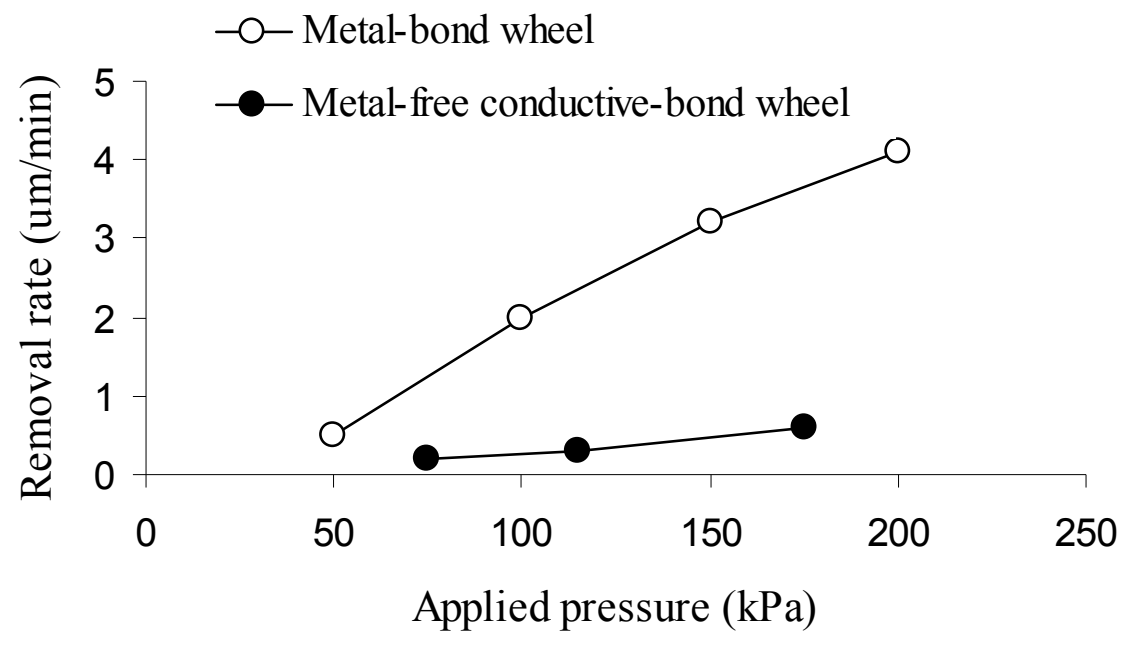

Fig. 16. Comparison of metal-free conductive-bond wheels and metal-bond wheels (after [21]). 
Table 1

Machines and wheel types used in ELID grinding of silicon wafers

\begin{tabular}{lccc}
\hline \multicolumn{1}{c}{ Machine } & Machine model & Wheel type & References \\
\hline Lapping machine & & Straight & {$[14]$} \\
& & & {$[21]$} \\
& & & {$[11]$} \\
$\begin{array}{l}\text { Horizontal spindle surface } \\
\text { grinder }\end{array}$ & SS-501 (Amada Wasino) & Straight & {$[16]$} \\
& & & \\
$\begin{array}{l}\text { Double side grinding } \\
\begin{array}{l}\text { Vertical spindle surface } \\
\text { grinder }\end{array}\end{array}$ & Straight & {$[24]$} \\
& & & Cup \\
\hline
\end{tabular}


Table 2

Summary of experimental results on ELID grinding of silicon wafers

\begin{tabular}{cc}
\hline Output variable studied & References \\
\hline Roughness & {$[13]$} \\
& {$[9]$} \\
& {$[14]$} \\
& {$[11]$} \\
Subsurface damage & {$[16]$} \\
& {$[21]$} \\
Material removal rate & {$[9]$} \\
& {$[11]$} \\
\end{tabular}


Table 3

Flatness requirements for $300 \mathrm{~mm}$ silicon wafers (year 2004 to 2006) (after [34])

\begin{tabular}{lccc}
\hline \hline Flatness Parameter & 2004 & 2005 & 2006 \\
\hline Global flatness (GBIR) & $<1 \mu \mathrm{m}$ & $<1 \mu \mathrm{m}$ & $<1 \mu \mathrm{m}$ \\
(also known as total thickness variation TTV) & & & \\
Site Flatness (SFQR) $(26 \mathrm{~mm} \times 33 \mathrm{~mm})$ & $<90 \mathrm{~nm}$ & $<80 \mathrm{~nm}$ & $<70 \mathrm{~nm}$ \\
\hline \hline
\end{tabular}

